\title{
Awareness on thalassemia and opinion of carrier screening among young women from selected undergraduate colleges of udupi district
}

\author{
Rishmitha ${ }^{\mathrm{a}}$, Sulochana Badagabettu ${ }^{\mathrm{a}, *}$, Archana $\mathrm{M} \mathrm{V}^{\mathrm{b}}$, Vani Lakshmi $\mathrm{R}^{\mathrm{c}}$, Jomon $\mathrm{C} \mathrm{U}^{\mathrm{a}}$ \\ ${ }^{a}$ Manipal College of Nursing, Manipal Academy of Higher Education, Manipal, Karnataka, India \\ ${ }^{\mathrm{b}}$ Division of Pediatric Hematology and Oncology, Kasturba Medical College, Manipal Academy of Higher Education, Manipal, Karnataka, India \\ ${ }^{c}$ Department of Data Science, Prasanna School of Public Health, Manipal Academy of Higher Education, Manipal, Karnataka, 576 104, India
}

\section{A R T I C L E I N F O}

\section{Keywords:}

Thalassemia

Awareness

Young women

Carrier screening

India

\begin{abstract}
A B S T R A C T
Introduction: Hemoglobinopathies are inherited disorders of red blood cells that poses significant cause of morbidity and mortality, impose a heavy burden on family. The study aims to assess the awareness of Thalassemia, and its willingness to screen among young women from Udupi district.

Methods: A descriptive cross-sectional survey design was employed to assess the awareness on Thalassemia among young women belonging to the age group of 18-24 years from selected undergraduate institutions of the Udupi district. The study used descriptive statistics, data visualization methods and chi-square tests.

Results: Among the 389 participants, $3(0.8 \%)$ of the participants reported Thalassemia in their families. Also, 28 (7.2\%) of the participants have a history of consanguineous marriage. $273(70 \%)$ participants reported Thalassemia is a lifetime condition, whereas $284(73 \%)$ believed that consanguinity does not increase the Thalassemia incidence. According to 275(70\%) respondents, premarital screening is not essential to rule out Thalassemia. The readiness of young women to screen for carrier status was estimated to be $57(15 \%)$, While $101(27 \%)$ were unwilling to screen, While 221 (58\%) were unsure about screening for carrier status. Based on Pearson's ChiSquared test, there was association between following variables: Age and Thalassemia awearness, $\left(\chi^{2}(4)=\right.$ 13.749, $\mathrm{p}<0.008)$, Education and Thalassemia awearness $\left(\chi^{2}(4)=10.864, \mathrm{p}<0.028\right)$, knowledge score and family income $\left(\chi^{2}(8)=21.100, \mathrm{p}<0.007\right)$.

Conclusion: The premise suggests a lack of awareness of Thalassemia disorder among young women, this calls for an urgent need to revise the Thalassemia control programme.
\end{abstract}

\section{Introduction}

Hemoglobinopathies are inherited red blood cell abnormalities that are common in many parts of the world. As a leading cause of illness and mortality, they place a significant burden on families. ${ }^{1}$ Thalassemia is an inherited blood disorder of red blood cell, characterized by reduced or missing production of one or more normal globin chains. Thalassemia syndromes are divided into two groups based on their phenotype: Transfusion-Dependent Thalassemias (TDTs) and Non-Transfusion -Dependent Thalassaemias (NTDTs). TDTs require regular blood transfusions to survive, and if they do not receive adequate transfusion support, they will suffer from a variety of complications resulting in a shorter life span. TDT patients include $\beta$ thalassemia major, severe $\mathrm{Hb}$ $\mathrm{E} / \beta$ thalassemia, transfusion - dependent $\mathrm{Hb} \mathrm{H}$ disease and surviving $\mathrm{Hb}$ Bart's hydrops fetalis. NTDT group patients include $\beta$ thalassemia intermedia, $\mathrm{Hb} \mathrm{E} / \beta$ thalassemia, and $\mathrm{Hb} \mathrm{H}$ disease. ${ }^{2}$

Thalassemia disorder affects 15 million people worldwide, and 240 million people have Thalassemic carrier status. Globally about 100,000 children are born with Thalassemia major, with 10,000 of them from India. The carrier rate for $\beta$-Thalassemia gene varies from 3 to $5 \%$ South Asia and 1-3\% in South India. India carries a substantial public health problem of Thalassemia. As per the National Health Mission (2016) report, there are approximately 1-1.5 lakh children with Thalassemia Major and nearly 42 million carriers of the $\beta$ Thalassemia trait. ${ }^{3}$ However, in India the reported average prevalence of Thalassemia carriers is $3-4 \%,{ }^{4}$ implies that there are $30-40$ million carriers in this multicultural and multilingual population of 1.3 billion people. ${ }^{5}$ Globally, 56,000 conceptions would have Thalassemia Major disorder. Among them, approximately 30,000 would have $\beta$-Thalassemia Major, with many babies being born in the middle- and low-income countries. ${ }^{6,7}$

\footnotetext{
* Corresponding author. Manipal College of Nursing, Manipal Academy of Higher Education, Manipal, Karnataka, 576104, India.

E-mail address: sulochana.k@manipal.edu (S. Badagabettu).
} 
$\beta$-Thalassemia is the most frequent inherited haemoglobin condition in the Indian subcontinent, with a contrasting distribution among the various endogenous groups. ${ }^{8}$ Being a multicultural country, India with a diversified population, an estimated $10.4 \%$ of the population chooses consanguineous marriage, increasing the manifestations of autosomal recessive illnesses.

Thalassemia is a chronic illness that requires lifelong treatment, which includes repeated blood transfusions, iron chelation and bone marrow transplant. ${ }^{9}$ This places a financial and emotional burden on the family and the healthcare system. Community-based public health efforts play a crucial role in the health and wellness of society at large. The vital preventative techniques include disseminating accurate information to the general public/experts, screening and counselling at-risk families, and screening the general population. These strategies facilitate the reduction of mortality and morbidity from Thalassemia in countries where it is prevalent. Premarital screening alone has tremendously decreased the birth prevalence of $\beta$-Thalassemia major. ${ }^{5,7}$ India's National Health Mission (2016) has placed a framework for preventing and managing hemoglobinopathies. ${ }^{10}$ One of the vital prerequisites to control Thalassemia was educating health professionals, school and college students, pregnant women, and the population at large. ${ }^{5} \mathrm{Com}-$ munity screening measures such as training and awareness programs on Thalassemia are urgently required where screening programmes significantly impact the detection of cases and disease management in low resource-constrained countries.

The current study attempts to understand how much young women aware about Thalassemia and its screening to realize the willingness to screen for carrier status. Awareness about Thalessemia and its screening will enable women to make life choices, including screening for carrier status and decision-making concerning consanguineous marriages. Early detection of carriers gives opportunities for informed choices for future decision making apart from bringing down the burden on the individual, family, and society.

\section{Methodology}

A descriptive cross-sectional survey design was employed for the study to assess the awareness of Thalassemia among young women belonging to the age group of 18-24 years from the selected government-aided undergraduate institutions of Udupi district. Prior permission was obtained from the administrators of the institutions for the smooth conduct of the survey. We designed a two-part questionnaire to collect data from participants. The first part included demographic information (age, education, family income, parents' educational status, family history, consanguineous marriage status, family history of congenital disease, and history of Thalassemia). The second part of the survey consisted of 20 items relating to Thalassemia awareness. This included facts associated with several aspects, including meaning, hereditary, classifications, disease presentations, diagnosis, complications, treatment and prevention. Each item had a correct answer which was assigned a score of " 1 " and a " 0 " otherwise (Table 2). The knowledge score ranged from 0 to 20 , and the scores were categorized based on tertile into Poor (0-7), Average (7-12) and Good (12-20). Experts in haematology, nursing, paediatrics, and community health contributed to ensuring the questionnaire's content validity. The reliability of the questionnaire was assessed by the split-half method $(\mathrm{r}=0.89)$.

In the subsequent section of the questionnaire, opinions on willingness to screen the carrier status among respondents were obtained through responses as 'Yes', 'No' and 'Not Sure'. Further statements on agreement and disagreement were obtained from participants who had indicated their opinion as Yes (willing for screening), No (not willing for screening) and Not Sure, (unsure of their willingness for screening) to learn and understand the reasons for willingness/unwillingness for screening expressed by the participants. The responses were categorized as Strongly Agree, Agree, Unsure, Strongly Disagree and Disagree. In addition, the participants were requested to share feedback on the
Table 1

Frequency and percentage of study participants $(\mathrm{N}=389)$.

\begin{tabular}{|c|c|c|}
\hline Variable & Frequency & Percentage \\
\hline \multicolumn{3}{|l|}{ Age in years } \\
\hline 18 & 143 & 36.8 \\
\hline 19 & 104 & 26.7 \\
\hline 20 & 114 & 29.3 \\
\hline 21 & 25 & 6.4 \\
\hline 22 & 3 & 0.8 \\
\hline \multicolumn{3}{|l|}{ Education } \\
\hline Bachelor of Arts & 22 & 5.7 \\
\hline Bachelor of Commerce & 189 & 48.6 \\
\hline Bachelor of science & 152 & 39.1 \\
\hline Bachelor of Business Management & 10 & 2.6 \\
\hline Bachelor of computer application & 16 & 4.1 \\
\hline \multicolumn{3}{|l|}{ Parent's education } \\
\hline Primary & 88 & 26.8 \\
\hline High school & 131 & 33.7 \\
\hline Senior secondary & 76 & 19.5 \\
\hline Undergraduate & 75 & 19.3 \\
\hline Postgraduate & 19 & 4.9 \\
\hline \multicolumn{3}{|l|}{ Family Income } \\
\hline$<5000$ & 68 & 17.5 \\
\hline $6000-15000$ & 120 & 30.8 \\
\hline $16000-25000$ & 84 & 21.6 \\
\hline $26000-35000$ & 44 & 11.3 \\
\hline 36000 and above & 73 & 18.8 \\
\hline \multicolumn{3}{|l|}{ History of consanguineous marriage } \\
\hline Yes & 28 & 7.2 \\
\hline No & 361 & 92.8 \\
\hline \multicolumn{3}{|l|}{ Degree of consanguinity } \\
\hline $1^{\text {st }}$ degree & 4 & 1.0 \\
\hline 2nd degree & 12 & 3.1 \\
\hline 3rd degree & 6 & 2.1 \\
\hline 4th degree & 6 & 2.1 \\
\hline \multicolumn{3}{|c|}{ Family member affected with Thalassemia } \\
\hline Yes & 3 & 0.8 \\
\hline No & 386 & 99.2 \\
\hline \multicolumn{3}{|c|}{ History of any congenital disease in the family } \\
\hline Yes & 11 & 2.8 \\
\hline No & 378 & 97.2 \\
\hline
\end{tabular}

survey to comprehend the reasons behind their choices abot rhe willness to screen.

The Institutional Ethics Committee (IEC:637/2020), Kasturba Hospital, Manipal approved the study protocol with CTRI Reg (No: CTRI/ 2021/01/039721). Prior permission was obtained from competent authorities of the participating institutions. Using the formulae to compute minimum sample size requirements for estimation of a proportion, we identified that the study requires a minimum sample size of 384 keeping the level of significance at $5 \%$ with an acceptable margin of error of $5 \%$ and anticipated population prevalence to be 0.50 .The particepents were selected randomly from the three undergraduate government-aided institutions in the Udupi district. Data was obtained online from participants upon their consent. The structured questionnaire was administered through Google Forms.

\subsection{Data analysis}

Descriptive statistics using frequency tables and percentages were used to describe the demographic characteristics of the respondents and their awareness about Thalassemia. Chi-Square and Fisher's Exact test were used to explore associations between the demographic variables and knowledge of Thalassemia, its screening process and the willingness to screen the carrier status. Subsequently, the researchers explored approaches to understand the sentiments of the study participants by reviewing their feedback on the survey and justification on their choice of decision to screen for the carrier status. The level of significance for the study was fixed at $5 \%$ and all statistical analyses were implemented using IBM SPSS 16.0 and Microsoft Excel. 
Table 2

Awareness on Thalassemia among young women $(\mathrm{N}=389)$.

\begin{tabular}{|c|c|c|c|}
\hline $\begin{array}{l}\text { SL } \\
\text { No }\end{array}$ & Items & $\begin{array}{l}\text { Correct } \\
\text { (Count, \%) }\end{array}$ & $\begin{array}{l}\text { Incorrect } \\
\text { (Count,\%) }\end{array}$ \\
\hline 1 & $\begin{array}{l}\text { Thalassemia is a condition in which the } \\
\text { human body is unable to produce healthy } \\
\text { RBCs }\end{array}$ & $220(56.6)$ & $169(43.4)$ \\
\hline 2 & $\begin{array}{l}\text { Hereditary disease can be passed down } \\
\text { through the genes. }\end{array}$ & $286(73.5)$ & $103(26.5)$ \\
\hline 3. & $\begin{array}{l}\text { In Southeast Asian countries, thalassemia is } \\
\text { a rare disease. }\end{array}$ & $99(25.4)$ & $290(74.6)$ \\
\hline 4 & Thalassemia is a lifelong disorder & $116(29.8)$ & $273(70.2)$ \\
\hline 5 & $\begin{array}{l}\text { Hereditary diseases like Thalassemia place } \\
\text { a financial strain on families. }\end{array}$ & $223(57.3)$ & $166(42.7)$ \\
\hline 6 & $\begin{array}{l}\text { Families are psychologically impacted by } \\
\text { hereditary diseases. }\end{array}$ & $221(56.8)$ & $168(43.2)$ \\
\hline 7 & $\begin{array}{l}\text { The common most thalassemia is } \beta \\
\text { thalassemia }\end{array}$ & $138(35.5)$ & $251(64.5)$ \\
\hline 8 & $\begin{array}{l}\text { In alpha thalassemia, the hemoglobin does } \\
\text { not produce enough alpha protein. }\end{array}$ & $167(42.9)$ & $222(57.1)$ \\
\hline 9 & $\begin{array}{l}\text { Consanguinity does not increase the } \\
\text { likelihood of hereditary diseases. }\end{array}$ & $105(27.0)$ & 284(73.0) \\
\hline 10 & $\begin{array}{l}\text { There is a } 25 \% \text { risk of conceiving a child } \\
\text { with Thalassemia Major if both males and } \\
\text { women are carriers. }\end{array}$ & $186(47.8)$ & 203(52.2) \\
\hline 11 & $\begin{array}{l}\text { Anaemia is a common symptom of } \\
\text { Thalassemia (low haemoglobin). }\end{array}$ & $227(58.4)$ & $162(41.6)$ \\
\hline 12 & $\begin{array}{l}\text { People with Thalassemia can accumulate } \\
\text { an excessive amount of iron in their } \\
\text { systems. }\end{array}$ & $109(28.0)$ & $280(72)$ \\
\hline 13 & $\begin{array}{l}\text { Thalassemia carriers show signs and } \\
\text { symptoms of the disease. }\end{array}$ & $174(44.7)$ & 215(55.3) \\
\hline 14 & $\begin{array}{l}\text { A blood test is performed to rule out the } \\
\text { possibility of being a Thalassemia carrier. }\end{array}$ & 189(48.6)) & $200(51.4)$ \\
\hline 15 & $\begin{array}{l}\text { To rule out hereditary disorders like } \\
\text { Thalassemia, premarital screening is not } \\
\text { required. }\end{array}$ & $114(29.3)$ & $275(70.7)$ \\
\hline 16 & $\begin{array}{l}\text { Individuals with Thalassemia can live a } \\
\text { normal life if they receive the proper } \\
\text { treatment. }\end{array}$ & 195(50.1) & 194(49.9) \\
\hline 17 & $\begin{array}{l}\text { Treatment is available that can cure the } \\
\text { Thalassemia disorder }\end{array}$ & $199(51.2)$ & $190(49.8)$ \\
\hline 18 & $\begin{array}{l}\text { Thalassemia can be treated with blood } \\
\text { transfusion }\end{array}$ & $174(44.7)$ & $215(55.3)$ \\
\hline 19 & Thalassemia disorder can be prevented & $184(47.3)$ & 205(52.7) \\
\hline 20 & $\begin{array}{l}\text { Blood transfusions on a regular basis are } \\
\text { harmful to the immune system. }\end{array}$ & 201(51.7) & $189(48.6)$ \\
\hline
\end{tabular}

\section{Results}

\subsection{Participant demographics}

The majority 143 (36.8\%) were 18 years old, 189(48.6\%) were persuing Graduation in Commerce stream. In terms of parental education, 131(33.7\%) of the parents had completed High school. Also, 130 (30.8\%) of the family's monthly income (in INR) was between ₹6000$₹ 15000$. The findings showed that three $(0.8 \%)$ of the participants reported having Thalassemia in their families, and $11(2.8 \%)$ of the family members had a history of congenital illness. According to the study, 28 (7.2\%) participants have a history of consanguineous marriage, and 4 $(1.0 \%)$ participants reported having parents with Ist Degree Consanguinity (Table 1 ).

The 20-item Thalassemia awareness questionnaire Table 2 had two response options: 'Yes' and 'No' with one correct answer The knowledge score was computed by counting the number of correct answers. Table 2 shows the frequency of correct and incorrect responses to each question. About 220(56.6\%) of respondents were aware that in some instances, the human body is unable to produce Red Blood Cells (RBCs). Thalassemia is a lifelong condition, according to over $273(70 \%)$ of the participants. Similarly, 251(65.0\%) of participants were aware that Thalassemia is the most common blood disorder, and 284(73.0\%) believed that consanguinity does not raise the incidence of Thalassemia.
Table 3

Association between demographic variables and thalassemia awearness.

\begin{tabular}{|c|c|c|c|c|c|c|}
\hline Variable & $\begin{array}{l}\text { Poor } \\
0-7\end{array}$ & $\begin{array}{l}\text { Average } \\
7-12\end{array}$ & $\begin{array}{l}\text { Good } \\
12-20\end{array}$ & $\chi^{2}$ & $\mathrm{df}$ & $\mathrm{p}$-value \\
\hline \multicolumn{7}{|l|}{ Age in years } \\
\hline 18 & 18 & 56 & 51 & 13.749 & 4 & $.008 *$ \\
\hline 19 & 32 & 32 & 40 & & & \\
\hline 20 & 55 & 57 & 30 & & & \\
\hline \multicolumn{7}{|l|}{ Education } \\
\hline Bachelor of Arts & 10 & 7 & 5 & 10.864 & 4 & $.028 *$ \\
\hline Bachelor of Commerce & 54 & 68 & 67 & & & \\
\hline Bachelor of science & 79 & 50 & 49 & & & \\
\hline \multicolumn{7}{|l|}{ Parent's education } \\
\hline Primary & 30 & 33 & 25 & 2.828 & 6 & .566 \\
\hline High school & 44 & 41 & 46 & & & \\
\hline Senior secondary & 27 & 25 & 24 & & & \\
\hline Graduate & 42 & 26 & 26 & & & \\
\hline \multicolumn{7}{|l|}{ Family Income } \\
\hline$<5000$ & 32 & 70 & 90 & 21.100 & 8 & $.007 *$ \\
\hline $6000-15000$ & 42 & 48 & 30 & & & \\
\hline $16000-25000$ & 39 & 22 & 23 & & & \\
\hline $26000-35000$ & 10 & 12 & 22 & & & \\
\hline 36000 and above & 20 & 26 & 27 & & & \\
\hline \multicolumn{7}{|c|}{ History of consanguineous marriage } \\
\hline Yes & 15 & 9 & 4 & 5.064 & 2 & .080 \\
\hline No & 128 & 160 & 170 & & & \\
\hline \multicolumn{7}{|c|}{ Family member affected with Thalassemia } \\
\hline Yes & 1 & 0 & 2 & 2.210 & 2 & .331 \\
\hline No & 142 & 125 & 119 & & & \\
\hline \multicolumn{7}{|c|}{ History of any congenital disease in the family } \\
\hline Yes & 137 & 122 & 190 & 1.665 & 2 & .435 \\
\hline No & 6 & 3 & 2 & & & \\
\hline
\end{tabular}

*: significant at $5 \%$ level of significance.

Hereditary disorders place a financial and psychological strain on families, according to $221(58 \%)$ and $223(57.0 \%)$ of respondents, respectively. According to $200(51 \%)$ of respondents, Thalassemia carrier status cannot be determined by a blood test, and 174(45\%) participants believed that blood transfusion is a treatment option for Thalassemia. Moreover, 275(70.7\%) respondents stated that premarital screening is not essential to rule out Thalassemia.

Furthermore, we categorized thalassemia awareness scores (9.06 \pm $5.08)$ into three categories namely: Good, Average, and Poor awareness based on tertiles. On this basis, we observed that 143 (36.8\%) young women had Poor awareness, 125 (36.8\%) had Average awareness and $121(32.1 \%)$ had good awareness.

\subsection{Association between demographic variables and thalassemia awareness scores}

The Pearson's chi-square test was used to explore associations between the Thalassemia awareness scores and the demographic characteristics. There was a statistically significant evidence of an association between Age and Thalassemia awareness, $\left(\chi^{2}(4)=13.749, \mathrm{p}<0.008\right)$, Education and Thalassemia awareness $\left(\chi^{2}(4)=10.864, \mathrm{p}<0.028\right)$, Knowledge score and Family Income $\left(\chi^{2}(8)=21.100, \mathrm{p}<0.007\right)$ (Table 3).

\subsection{Opinion on willingness towards carrier screening for thalassemia}

The readiness of young women to screen for carrier status was estimated to be 57(15.0\%); of which $19(33.3 \%)$ strongly agree and 33 (57.8\%) agree with the statement that screening "prevents transmission to offspring". Also, 23(40.6\%) participants strongly agreed and 26 (46.3\%) agree with the statement that screening "prevents disease transmission" (Figs. 1 and 2).

Among the 101(27.0\%) who were unwilling for screening for carrier status; $22(21.7 \%)$ had strongly agreed and $43(42.5 \%)$ agreed on the statement that screening "may not be in favour of my choice". Also, 22 (21.1\%) participants strongly agreed for the statement "I won't carry 


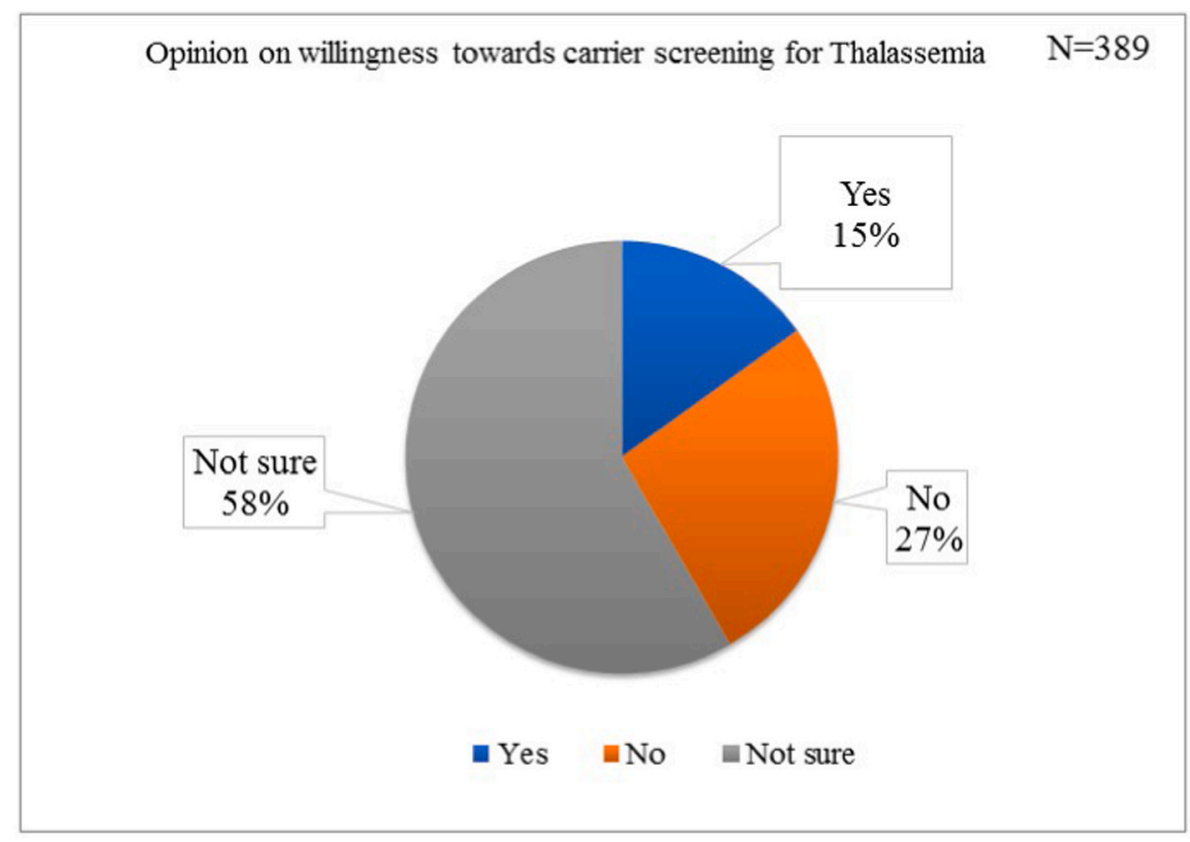

Fig. 1. Willingness towards carrier screening for thalassemia.

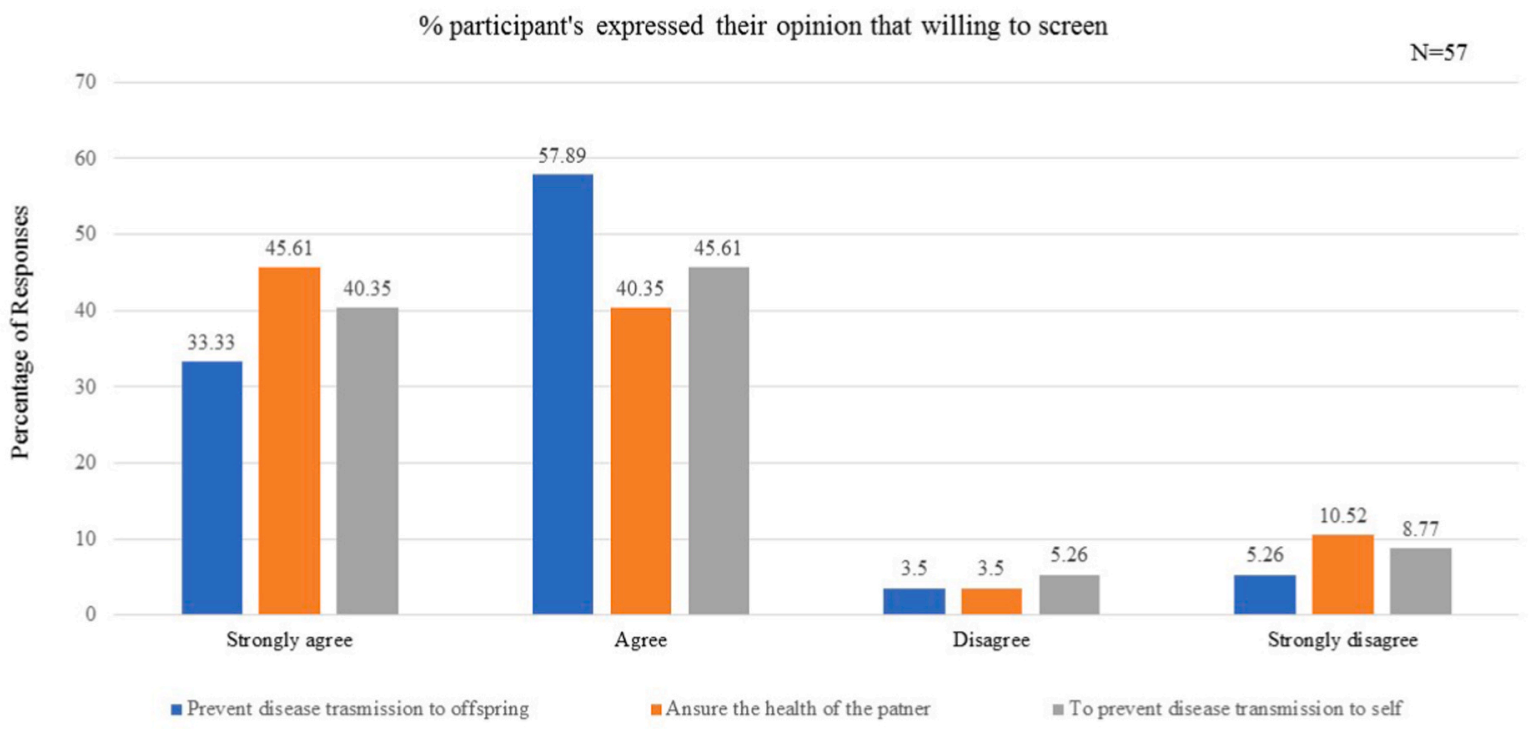

Fig. 2. Reason for willingness towards carrier screening for thalassemia.

this illness and 29(28.7\%) disagreed for premarital screening and 36 (35.6\%) were not interested to screen. (Fig. 4).

Further, a sentiment analysis-based approach was employed to identify the premises behind the lack of willingness to screen for Thalassemia based on qualitative information collected from the participants. A graphical representation of the same is presented in (Fig. 3). Sentiment analysis of participants illustrated that among the 331 (85.31\%) participants who were unsure or unwilling to undergo the carrier screening, 18 participants $(72.00 \%)$ found that the survey was informative, $19(86.36 \%)$ felt grateful, $41(87.23 \%)$ were appreciative of the efforts and $12(92.31 \%)$ were curious to more on the topic. These participants have detailed on the need for more awareness on Thalassemia and more information pertaining to the carrier screening. The researchers feel that public awareness will enhance the willingness to screen for Thalassemia.

\section{Discussion}

Hemoglobinopathies are common in South Asia, notably India, due to a range of genetic combinations and the incidence of thalassaemia carriers. ${ }^{11}$ In Indian societies, consanguineous marriages are traditionally and socially valued, accounting for $20-50 \%$ of all weddings, ${ }^{12}$ and this survey also revealed $28(7.0 \%)$ of consanguineous marriages among the family members of the participants. According to the current study, 3 $(0.8 \%)$ of the participants reported having people with Thalassemia in the family, which corroborate the findings of a study led by Murthy et al., in 2015 , only $4 \%$ of medical students and $5.3 \%$ of non-medical students reported having a family member or blood relative who was suffering from Thalassemia. ${ }^{13}$

The study results provided valuable insights into young women's awareness, opinions, and needs on Thalassemia. The importance of Thalassemia awareness among women is critical, and it may aid in its 


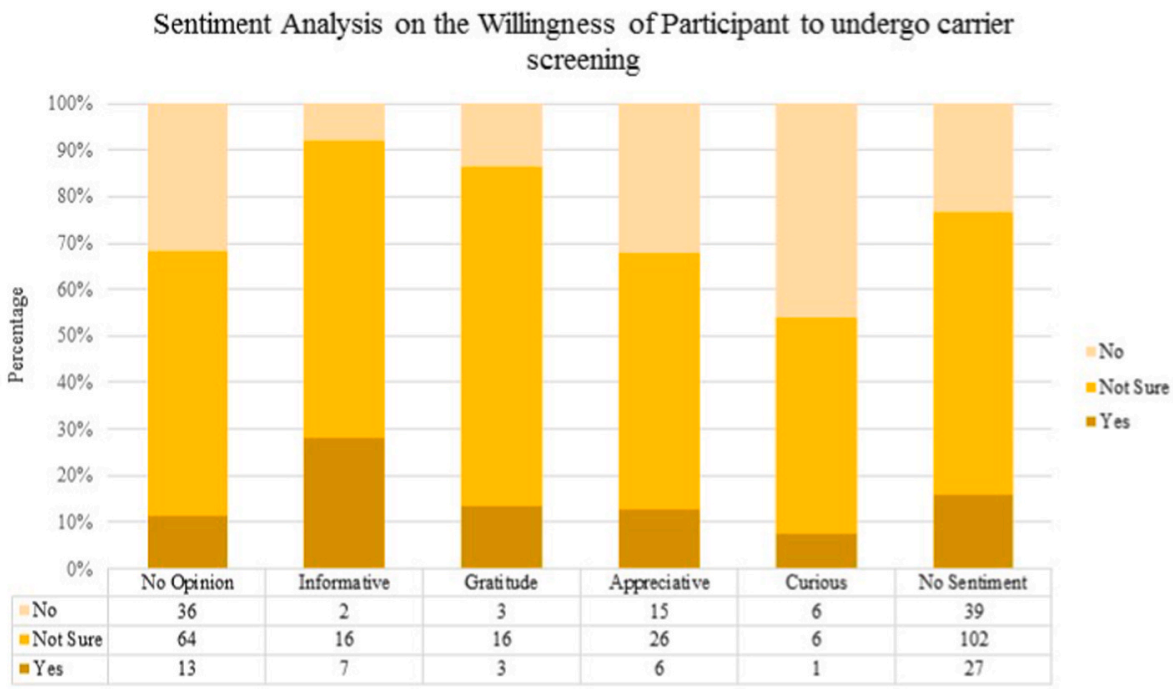

Fig. 3. Sentiment Analysis on the Willingness of Participant to undergo Diagnostic Test.

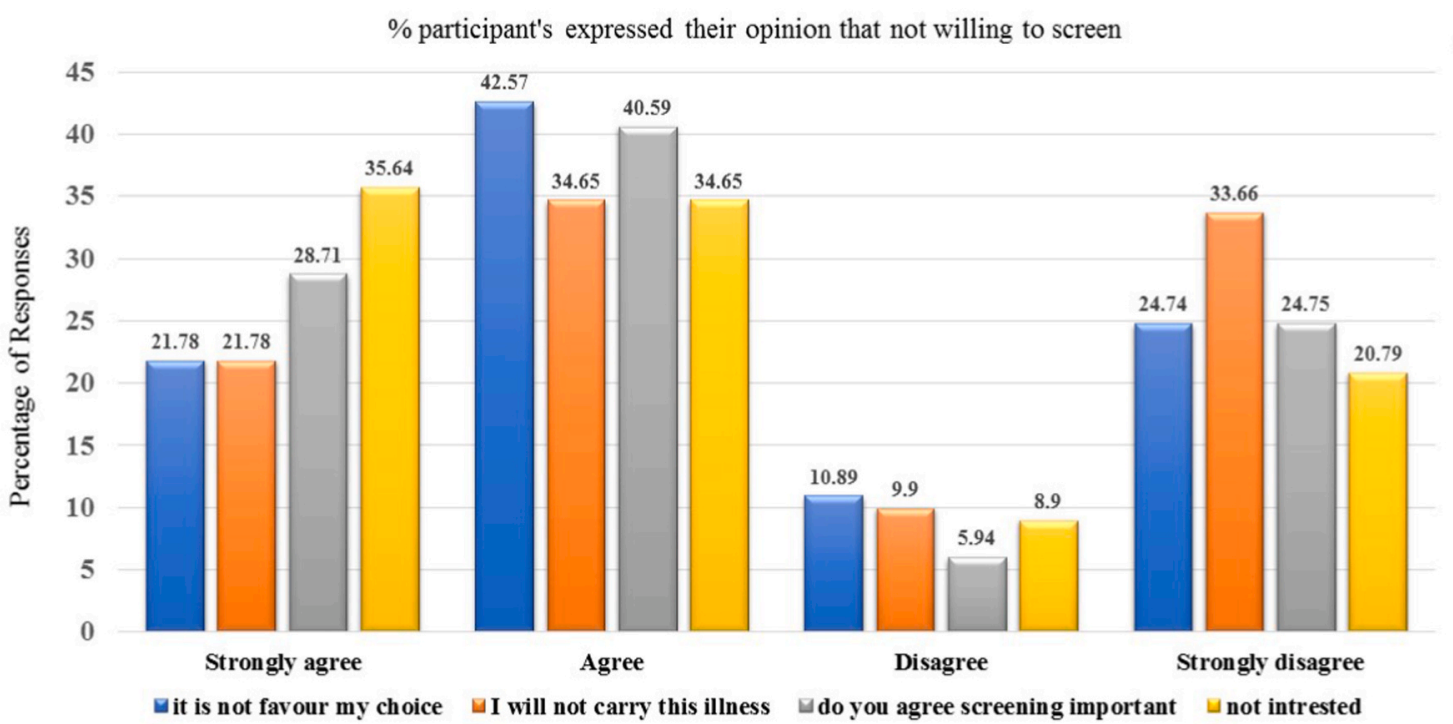

Fig. 4. Reason for unwillingess towards carrier screening for Thalassemia.

prevention in the family. Thalassemia education campaigns would be one of the goals of the National Health Mission, and this study clearly shows that more awareness is needed, as only 116(30.8\%) of the participants were aware that Thalassemia is a lifelong disease, and 99 (25.4\%) were unfamiliar with a disease that is common in South Asia and 227(58.3\%) of participants answered that Anemia is a common symptom in Thalassemia disorders. The current finding supports the study results from Malaysia study done among medical and non-medical students and a study from Indonesia. ${ }^{13,14}$ Most of the participants 284 (73\%) were unaware that consanguinity plays a role in Thalassemia and $215(55 \%)$ of them reported that they are not aware that Thalassemia can be treated with blood transfusion. Awareness of Thalassemia was inadequate among the participants and a study from Malaysia on public perceptions and attitudes toward Thalassemia found similar results. ${ }^{15}$

The study shows that $57(15.0 \%)$ of the participants were willing to screen for Thalassemia and 101(27.0\%) were not willing, but 231 (58.0\%) were unsure about screening. These findings strongly support the need for participants to receive an education drive on Thalassemia education at the educational institution will empower and raise awareness on thalassemia and screen carriers. This approach studied by ${ }^{16}$ recognized the need for awareness of Thalassemia and screening for carrier status and antenatal diagnosis in at-risk couples.

In the present study, the knowledge component has a statistically significant association with age $(\mathrm{p}<0.008)$, education $(\mathrm{p}<0.028)$, and family income $(\mathrm{p}<0.007)$.Higher scores and hence better awareness, was attributed to the internet accessibility as reported by the particepents. Sentiment analysis revealed that awareness deficits could be a critical factor in reluctance to screen for Thalassemia.

\subsection{Study limitations}

The Covid-19 pandemic has severely impacted studies involving data collection from participants. The researchers were forced to complete the data collection process through online mode without any face-toface interactions. The study considered a proportionate sampling technique for sample selection due to the varying numbers of study participants from each section of the selected colleges. However, this could not be accomplished due to the pandemic-induced regulations. The educational instruction was designed for young women and offered via virtual mode, thus avoiding one to one live nteraction with in which may have 
significantly benefitted the researchers and the student community.

The study participants reported having Thalassemia among family members and a history of consanguineous marriage. Thus, educational programmes should be extended to the high risk and easily accessible population. The current study suggests a need for health literacy on Thalassemia programs at the local level. A pre-and post-study would be preferable, as study participants raised worries about not having heard about Thalassemia and needing more knowledge through informative sessions. Finally, there are only a handful of public health studies on Thalassemia in India. Hence, extensive community-oriented studies are the need of the hour in order to enhance awareness, facilitate early detection and minimize the risks associated with Thalassemia.

\section{Conclusions}

The study highlights that the most of the participants were unaware of Thalassemia and the significance of carrier screening, lack of information and obliviousness associated with 'Thalassemia'. A comprehensive preventive programme should be implemented because premarital screening is one of the essential strategies for preventing genetic disorders such as Thalassemia. Based on the study, the following are the recommendations: The importance of early Thalassemia education should be highlighted and made available to colleges, universities, and the general public, as well as premarital screening services for young people in colleges and universities for early detection, which may reduce high-risk marriages.

\section{Funding}

We have not received any funding for the study.

\section{Submission declaration}

This work has never been published or is currently being considered for publication elsewhere. All authors and the responsible authorities approve the publication in the areas where work has been completed. If accepted, it will not be published elsewhere without the written permission of the copyright holder.

\section{Declaration of competing interest}

The authors report no conflicts of interest. The authors alone are responsible for the content and writing of this article.

\section{Acknowledgements}

The authors express their gratitude to the female students of Mahatma Gandhi Memorial College, Udupi, Sri Bhuvanendra College, Karkala, and Bhandarkars' Arts and Science College, Kundapura for their valuable participation in answering the questionnaire through online mode, which greatly aided in completing this study.

\section{References}

1 Weatherall DJ, Clegg JB. The Thalassaemia Syndromes. Oxford; Malden, MA: Blackwell Science; 2001.

2 2021. Guidlines for the Management of Tranfusion Dependent Thalassaemia (TDT). Thalassamia International Fedaration; 2014.

3 Verma I, Choudhry V, Jain P. Prevention of thalassemia: a necessity in India. Indian J Pediatr. 1992;59:649-654.

4 Mohanty D, Colah RB, Gorakshakar AC, et al. Prevalence of $\beta$-thalassemia and other haemoglobinopathies in six cities in India: a multicentre study. J. Commun. Genet. 2013;4:33-42.

5 Colah R, Italia K, Gorakshakar A. Burden of thalassemia in India: the road map for control. Pediatr. Hematol. Oncol. J. 2017;2:79-84.

6 Madan N, Sharma S, Sood SK, Colah R, Bhatia LH. Frequency of $\beta$-thalassemia trait and other hemoglobinopathies in northern and western India. Indian J Hum Genet. 2010;16:16-25.

7 Verma I, Saxena R, Kohli S. Past, present \& future scenario of thalassaemic care \& control in India. Indian J Med Res. 2011;134:507-521.

8 Weatherall D. The inherited disorders of haemoglobin: an increasingly neglected global health burden. Indian J Med Res. 2011;134:493-497.

9 Srivastava A, Shaji RV. Cure for thalassemia major - from allogeneic hematopoietic stem cell transplantation to gene therapy. Haematologica. 2017;102:214-223.

10 New Dehli. NHM Guidlines on Prevention and Control of Hemoglobinopathies in IndiaThalassemias, Sickle Cell Diseases and Other Varient Hemoglobins. 2016, 1-138.

11 Fucharoen S, Winichagoon P. Haemoglobinopathies in southeast Asia. Indian J Med Res. 2011;134:498-506.

12 Chakravartti MR. Consanguinity in India. Z Morphol Anthropol. 1968;60:170-183.

13 Vasudeva Murthy CR, Zulkeflle MZAB, Venkateswaran SP, Barua A. Knowledge, awareness and participation of medical and non-medical students in the Malaysia national thalassemia prevention programme. Int J Hum Genet. 2015;15:61-72.

14 Sahiratmadja E, Panigoro R. Awareness and willingness to be screened for thalassemia carrier status of medical students from bandung, Indonesia. Hemoglobin. 2019;43, 360-360.

15 Wong LP, George E, Tan J-AMA. Public perceptions and attitudes toward thalassaemia: influencing factors in a multi-racial population. BMC Publ Health. 2011;11:193.

16 Saxena A, Phadke SR. Feasibility of thalassaemia control by extended family screening in Indian context. J Health Popul Nutr. 2002;20:31-35. 